\title{
Level of IMA in newly diagnosed untreated hypothyroid subjects diagnosed during routine screening at Tertiary Care Hospital in North India
}

\author{
Poonam Agrawal ${ }^{1, *}$, Niket Verma ${ }^{2}$, Binita $^{3}$, Sumita Sethi ${ }^{4}$, Pratima $^{5}$ \\ ${ }^{1,3,4}$ Associate Professor, ${ }^{2}$ Assistant Professor, ${ }^{5}$ Professor \& HOD,,${ }^{1,3}$ Dept. of Biochemistry, ${ }^{2}$ Dept. of Medicine, ${ }^{4}$ Dept of \\ Opthalmology, ${ }^{5}$ Dept. of Pathology, ${ }^{1,2}$ Army College of Medical Sciences, Delhi Cantt, New Delhi, Delhi, ${ }^{3}$ Maulana Azad \\ Medical College, New Delhi, Delhi, ${ }^{4}$ BPS Government Medical College, Sonipat, Haryana, ${ }^{5}$ Dr Baba Sahib Ambedkar Medical \\ College and Hospital, New Delhi, Delhi, India
}

*Corresponding Author:

Received: $31^{\text {st }}$ October, 2017

Email: drpoonam24agrawal@yahoo.com

Accepted: $30^{\text {th }}$ January 2018

\begin{abstract}
Introdcution: Aim of this study was to assess the level of ischemia modified albumin(IMA) in newly diagnosed untreated hypothyroid subjects.

Materials and Methods: Serum IMA assessment was done by Barr et al method 30 newly diagnosed patients of hypothyroidism For the control group 50 normal healthy euthyroid adults were selected. TSH was done by one-step sandwich ELISA, and fT3, fT4 was done by one-step competitive ELISA method. Data were presented as mean \pm standard deviation (SD).

Results: Serum IMA was not found to be statistically different between hypothyroid and euthyroid control group.

Conclusion: Contrary to the findings of majority of studies done on this subject, our study has not shown any significant elevation of IMA in hypothyroid subjects as compared to euthyroid subjects. IMA level in subjects of hypothyroidism has been a controversial issue since long. Assessment of cIMA should be done in association with other oxidative stress marker, and their correlation if any should be studied in a large cohort.
\end{abstract}

Keywords: IMA, cIMA, Hypothyroid, Oxidative stress.

\section{Introduction}

Human serum albumin (HSA) is synthesized in the liver and it is the most abundant protein in blood. Normal concentration of this protein is $3.5-5.0 \mathrm{~g} / \mathrm{dl}$. Its $\mathrm{N}$ terminus amino acid sequence is quite specific to human and some studies in past have shown that this $\mathrm{N}$ terminus amino acid sequence is primary binding site for transition metal like copper and cobalt. This metal binding site in HSA is very much prone for damage on exposure to ischemia compare to albumin from other species. This modification of a very small fraction of the human serum albumin results in the production of a modified form of the albumin known as ischemia modified albumin (IMA), which shows reduced cobalt binding to modifies $\mathrm{N}$ terminal. ${ }^{1}$ Precise mechanism which is responsible for production of such modified albumin in condition of ischemia is yet unknown but many studies have indicated that various factors like free radical damage, acidosis, membrane energy dependent sodium and calcium pump disruption ,reduced oxygen tension may be possible culprit for such modification of albumin. ${ }^{2}$

This concept has lead to development of a method to detect the level of IMA which was previously known as ACB (Albumin Cobalt Binding) assay since it is based on reduced binding of modified albumin to the cobalt ion in patients of ischemia and oxidative stress.

Initially thought to be a marker of cardiac ischemia it was found to be deranged in various other ischemic like state like systemic sclerosis, peripheral vascular disease, skeletal muscle ischemia, glaucoma, diabetes etc. $^{3-8}$

Hypothyroidism is the state of under regulation of metabolism where BMR is decreased due to low level of thyroid hormones. Level of IMA in hypothyroid subjects has always been a matter of debate. In spite of good number of studies studying the level of IMA in hypothyroid subjects, there is no consensus among them . At one end studies have shown increased level of IMA in cases of hypothyroidism, while at the same times studies have shown lower level of IMA. ${ }^{9-10}$ There are even studies which have not found any difference in the level of IMA in normal control and hypothyroid subjects . ${ }^{11}$

Hence this study was planned to study the level of IMA in newly diagnosed subjects of hypothyroidism who were not on any treatment.

\section{Aim and objective}

This study was aimed to estimate the level of IMA in newly diagnosed hypothyroid subjects.

\section{Materials and Methods}

This study was an observational, prospective, case control study done to assess the level of IMA in newly diagnosed hypothyroid subjects.

30 newly diagnosed patients of hypothyroidism who were accidently diagnosed to be hypothyroid during routine screening in the lab of a tertiary care hospital of North India were recruited for the study 
after getting their informed written consent. Cut off for $\mathrm{TSH}$ level to diagnose hypothyroidism was kept at equal or more than $5.5 \mathrm{microIU} / \mathrm{ml}$.

For the control group 50 normal healthy euthyroid adults having equal number of male and female in age group 40-60 years were selected. They were either the relative of the patients who accompanied the patients to the OPD or the volunteers from the Department of Biochemistry and Medicine. They were recruited for the study only after getting their informed written consent.

For both the groups following exclusion criteria were adopted:

1. Subjects with cancers, hypertension, renal and hepatic diseases or any other acute/chronic illness were not included in the study

2. Pregnant and postmenopausal ladies were also not included in the study

\section{Biochemistry measurements}

Serum IMA assessment was done by Barr et al method $^{12}$ according to which $200 \mu \mathrm{l}$ of serum was added to $50 \mu \mathrm{l}$ of $\mathrm{CoCl}_{2} .6 \mathrm{H} 2 \mathrm{O}(1 \mathrm{gm} / \mathrm{L})$ in a test tube. After gentle mixing, test tube was kept at room temperature for $10 \mathrm{~min}$ for incubation to allow adequate

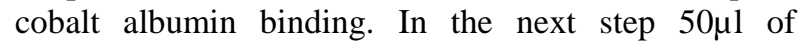
DTT(1.5 g/L) was added in the test tube and after proper mixing incubation was done at room temperature for 2 minutes. Next $1 \mathrm{ml}$ of $\mathrm{NaCl}$ was added and colour developed was measured colorimetrically at $470 \mathrm{~nm}$.

Blank test tube was prepared in similar fashion. The only difference of blank test tube preparation was that $50 \mu \mathrm{l}$ of water was added instead of DTT. IMA reading of test and blank was recorded as absorbance unit (ABSU).

Level of TSH was assessed by one-step sandwich ELISA, and fT3, fT4 was assessed by one-step competitive ELISA method.

\section{Statistical Analysis}

Data were presented as mean \pm standard deviation (SD). Independent sample t-test was used to determine statistical differences across the patient and control groups. The Pearson's correlation analysis was performed to evaluate the between variable associations in the hypothyroid patient group. Statistical significance was considered at $\mathrm{p}<0.05$. Data were analyzed using SPSS version 20.0 for Windows (SPSS Inc, Chicago, IL, USA).

\section{Results}

Between groups differences in the mean \pm SD of various parameters studied by independent variable $\mathrm{t}$ test are presented in Table 1. There were no significant difference in Age, BMI, and FBS between control and patient groups. As expected serum TSH level was found to be significantly elevated in hypothyroid subjects $(7.8 \pm 3.7$ vs $2.3 \pm 1.1 \mathrm{p}=0.00)$. Values of FT3 and FT4 though lower in hypothyroid subjects compared to control population, the difference was not found to be statistically significant $(p>0.05)$.Though the serum IMA was found to be elevated in hypothyroid patient group as compared to euthyroid control group, the difference was not found to be statistically significant $(0.09 \pm 0.07$ vs $0.07 \pm 0.04 \mathrm{p}=0.09)$.

Table 1: Study variables among euthyroid control and hypothyroid patient groups

\begin{tabular}{|l|c|c|c|}
\hline Variable & $\begin{array}{c}\text { Euthyroid } \\
(\mathbf{n = 5 0 )}\end{array}$ & $\begin{array}{c}\text { Hypothyroid } \\
\text { Patients } \\
(\mathbf{n = 3 0})\end{array}$ & p-value \\
\hline Age & $37.4 \pm 11.7$ & $38.6 \pm 8.5$ & 0.93 \\
\hline BMI & $25.9 \pm 6.3$ & $23.9 \pm 4.4$ & 0.13 \\
\hline TSH & $2.3 \pm 1.1$ & $7.8 \pm 3.7$ & 0.00 \\
\hline FT3 & $6.6 \pm 1.1$ & $6.3 \pm 1.2$ & 0.22 \\
\hline FT4 & $18.2 \pm 4.1$ & $17.9 \pm 4.4$ & 0.76 \\
\hline FBS & $99.3 \pm 27.1$ & $98.2 \pm 14.8$ & 0.83 \\
\hline IMA & $0.07 \pm 0.04$ & $0.09 \pm 0.07$ & 0.09 \\
\hline
\end{tabular}

\section{Discussion}

Contrary to the findings of majority of studies done to detect level of IMA in hypothyroid subjects, our study has not shown any significant elevation of IMA in hypothyroid subjects as compared to euthyroid subjects $(0.09 \pm 0.07$ vs $0.07 \pm 0.04 \mathrm{p}=0.09)$. Level of IMA in hypothyroidism has been a controversial issue since long. Reddy SV et $\mathrm{al}^{9}$ have shown increased IMA in both overt and subclinical hypothyroidism and have shown significant positive correlation of IMA with
TSH in overt hypothyroidism. In yet another study done by Ma S.G et al, IMA was found to be higher in overt hypothyroidism. In their study IMA was seen to be inversely correlated with FT3 and FT4. ${ }^{13}$ Contrary to the findings in above studies, Ersoy et al have not found any statistical difference in IMA level in hypothyroid subjects compared to euthyroid group. ${ }^{11}$ Tthere are even studies which have shown rather lower values of IMA in hypothyroid subjects. Once $M$. et al have shown IMA level to be even low in hypothyroid subjects compared to euthyroid group which they have 
explained may be due to hypometabolism in hypothyroidism. ${ }^{10}$

IMA has been developed as a marker of oxidative stress in 1990. Oxidative stress is a state of imbalance where ROS exemplified by free radical overpowers the body defence mechanism antioxidant system. ${ }^{14}$ Initially IMA was studied as a marker in acute coronary syndrome in the setting of ischemia reperfusion. ${ }^{15-17}$ Soon it was found to be elevated in noncardiac ischemic conditions like skeletal muscle, cerebral, gastrointestinal, pulmonary ischemia as well as in diseases where free radical overproduction occurs like liver cirrhosis ,infection, and malignancy. ${ }^{18-22}$ Ozgur et al have even shown IMA to be a more efficient marker compare to TAS( total antioxidative status) and TOS (total oxidative status) in patients with multiple sclerosis. $^{23}$

Researchers have found raised IMA level in addition to raised level of TOS, OSI in bladder cancer patients, but when corrected for albumin, value of cIMA was not found to be different statistically. ${ }^{24}$ Similar observation was made when a cohort of colorectal cancer was studied in a different study by different researchers ${ }^{25}$ where though the level of IMA was seen to be elevated in diseased group, when the correction was done cIMA was not found to be statistically different in diseased and control group. . These findings denote that assessment of IMA alone may be deceptive to assess the oxidative stress state, rather assessment of corrected IMA (cIMA) may be more accurate.

State of oxidative stress in hypothyroidism itself has been a controversial issue since long. Number of studies have shown increased oxidative stress as exemplified by the increased level of $\mathrm{MDA}^{26,27}$ or Nitric oxide in hypothyroid subjects ${ }^{28}$ or deficient antioxidant defence mechanism in the form of decreased activity of SOD, decreased level of FRAP and GSH. ${ }^{29}$ At the same time there are few studies which have shown no elevation of oxidative stress marker in hypothyroid subjects..$^{30,31}$ According to these researchers hypothyroidism being a hypo metabolic state due to deficiency of thyroid hormone does not promote mitochondrial oxygen utilization and generation of free radical. Lack of oxidative stress in hypothyroid subjects thus maybe a reason for no increase of level of IMA which itself is a marker of oxidative stress.

Another possibility of no significant alteration in the level of IMA in our study may be that most of the studies who have assessed the level of IMA in hypothyroid subjects have included the patients of longer duration compare to patients in our study group which were newly diagnosed patients of hypothyroidism who were accidently diagnosed during routine screening and must be mostly the cases of only short or very short duration. Duration of underlying disease play important role in generation of free radical, so in all possibility our study group patients though had hypothyroidism, the illness was of short duration which had not exposed the effected individual to oxidative stress to that an extent which can alter the albumin to generate IMA.

\section{Conclusion}

Our study has shown no significant elevation of IMA in hypothyroid subjects. This may be either due to the fact that diseased group selected were newly diagnosed cases of hypothyroid which yet not have developed the oxidative stress to the extent which can raise IMA. Another possibility may be that hypothyroid state itself being a hypo metabolic state does not pose a threat for oxidative stress so not affecting the IMA level. The correction/adjustment of IMA level should be done in all cases to find its true relation with the disease state. With this we conclude that the assessment of cIMA should be done in association with other oxidative stress marker, and their correlation if any should be studied in a larger cohort.

\section{References}

1. Christenson RH, Doh SH, Sanhai WR, Holtman V, et al. Characteristics of an albumin cobalt binding test for assessment of acute coronary syndrome patients: a multicenter study.Clin Chem 2001;47:464-70.

2. Berenshtein E,Mayer B, Goldberg C, Kitrossky N, Chevion M. Patterns of mobilization of copper and iron following myocardial ischemia. Possible predictive criteria for tissue injury. J Mol Cell Cardial 1997;29:3025-34.

3. Montagnana M,Lippi G. Volpe A, et al. Evaluation of cardiac laboratory markers in patients with systematic sclerosis. Clin Biochem 2006;39:913-7.

4. Roy D, Qulies J, Sharma R, et al. Ischemia -modified albumin concentrations in patients with peripheral vascular disease and exercise - induced skeletal muscle ischemia. Clin Chem 2004;50:1656-60.

5. Chang D, Sha Q, Zhang X, et al. The evaluation of the oxidative stress parameters in patients with primary angle-closure glaucoma. PLoS One 2011;6:e27218.

6. Piwowar A, Knapik-Kordecka M, Warwas M. Ischemiamodified albumin level in type 2 diabetes mellitus Preliminary report. Dis Markers. 2008;24(6):311-7

7. Fidan E, Mentese A, Kavgaci H, Orem A, Fidan S, Uzun A, Ozdemir F, Aydin F.Increased ischemia-modified albumin levels in patients with gastric cancer.Neoplasma. 2012;59(4):393-7

8. Stachowicz-Stencel T, Synakiewicz A, Owczarzak A, Sliwińska A, Aleksandrowicz-Wrona E, LysiakSzydowska W, Balcerska A. Ischemia-modified albumin as a biochemical marker in children with neuroblastoma and soft tissue sarcomas. J Clin Lab Anal. 2011;25(4):255-8.

9. Reddy SV, Suchitra MM, Pradeep V, Alok S, Suresh V, Bitla AR, Srinivasa Rao PV. Ischemia-modified albumin levels in overt and subclinical hypothyroidism. $\mathrm{J}$ Endocrinol Invest. 2015 Aug;38(8):885-90.

10. Oncel M, Kryıc1 A, Onen S. Evaluation of the Relationship Between Ischemia-Modified Albumin 
Levels and Thyroid Hormone Levels. J Clin Lab Anal.2015 Nov;29(6):427-31.

11. Ersoy K, Anaforoğlu İ, Algün E. Serum ischemic modified albumin levels might not be a marker of oxidative stress in patients with hypothyroidism. Endocrine.2013 Apr;43(2):430-3.

12. Bar-Or D, Lau E, Winkler JV. A novel assay for cobaltalbumin binding and its potential as a marker for myocardial ischemia-a preliminary report. J Emerg Med. 2000 Nov;19(4):311-5.

13. Ma SG, Yang LX, Bai F, Xu W, Hong B. Ischemiamodified albumin in patients with hyperthyroidism and hypothyroidism. Eur J Intern Med. 2012 Sep;23(6):e13640.

14. Roy D, Quiles J, Gaze DC, Collinson P, Kaski JC, Baxter GF. Role of reactive oxygen species on the formation of the novel diagnostic marker ischaemia modified albumin. Heart. 2006 Jan;92(1):113-4.

15. Sinha MK, Gaze DC, Tippins JR, Collinson PO, Kaski JC. Ischemia modified albumin is a sensitive marker of myocardial ischemia after percutaneous coronary intervention. Circulation. 2003 May 20;107(19):2403-5.

16. Sinha MK, Roy D, Gaze DC, Collinson PO, Kaski JC. Role of "Ischemia modified albumin", a new biochemical marker of myocardial ischaemia, in the early diagnosis of acute coronary syndromes. Emerg Med J. 2004 Jan;21(1):29-34.

17. Peacock F, Morris DL, Anwaruddin S, Christenson RH, Collinson PO, Goodacre SW, Januzzi JL, Jesse RL, Kaski JC, Kontos MC, Lefevre G, Mutrie D, Sinha MK, Uettwiller-Geiger D, Pollack CV. Meta-analysis of ischemia-modified albumin to rule out acute coronary syndromes in the emergency department. Am Heart J. 2006 Aug;152(2):253-62.

18. Keating L, Benger JR, Beetham R, Bateman S, Veysey S, Kendall J, Pullinger R. The PRIMA study: presentation ischaemia-modified albumin in the emergency department. Emerg Med J. 2006 Oct;23(10):764-8.

19. Hacker M, Hoyer HX, la Fougere C, et al. Effects of peripheral vascular intervention on ischemia modified albumin. Coron Artery Dis 2007; 18:375-9.

20. Seneş M, Kazan N, Coşkun O, Zengi O, Inan L, Yücel D. Oxidative and nitrosative stress in acute ischaemic stroke. Ann Clin Biochem. 2007 Jan;44(Pt 1):43-7.

21. Turedi S, Gunduz A, Mentese A, Karahan SC, Yilmaz SE, Eroglu O, Nuhoglu I, Turan I, Topbas M. Value of ischemia-modified albumin in the diagnosis of pulmonary embolism. Am J Emerg Med. 2007 Sep;25(7):770-3.

22. Gunduz A, Turkmen S, Turedi S, Mentese A, Yulug E, Ulusoy H, Karahan SC, Topbas M. Time-dependent variations in ischemia-modified albumin levels in mesenteric ischemia. Acad Emerg Med. 2009 Jun;16(6):539-43.

23. Aydin O, Ellidag HY, Eren E, Kurtulus F, Yaman A, Y1lmaz N. Ischemia modified albumin is an indicator of oxidative stress in multiple sclerosis. Biochem Med (Zagreb). 2014 Oct 15;24(3):383-9.

24. Srivatsan R, Das S, Gadde R, Manoj-Kumar K, Taduri S, Rao N, Ramesh B, Baharani A, Shah K, Kamireddy SC, Priyatham G, Balakumaran TA, Balakumaran SS, Kamath A, Rao A. Antioxidants and lipid peroxidation status in diabetic patients with and without complications. Arch Iran Med. 2009 Mar;12(2):121-7.

25. Ellidag, H. Y, Bulbuller, N., Eren, E., Abusoglu, S., Akgol, E., Cetiner, M., \& Yılmaz, N. (2013). IschemiaModified Albumin:Could It Be a New Oxidative Stress Biomarker for Colorectal Carcinoma? Gut and Liver, 7(6), 675-680.
26. Jayati Roy Choudhury, Amrita Karmakar, Barnita Guha, Brahmarshi Das and Jayanta Kumar Rout. Ischaemia Modified Albumin and Malondialdehyde Level in Subjects Suffering from Hypothyroidism.International Journal of Biochemistry Research \& Review, ISSN: 2231-086X,Vol.: 7, Issue.:3

27. Nanda N, Bobby Z, Hamide A, Koner BC, Sridhar MG. Association between oxidative stress and coronary lipid risk factors in hypothyroid women is independent of body mass index. Metabolism. 2007 Oct;56(10):1350-5.

28. Dahiya K, Verma M, Dhankhar R, Singh V, Ghalaut PS, Seth S. Alteration of ischemia modified albumin and nitric oxide levels in hypothyroidism. Clin Lab.2014;60(6):969-72.

29. Reddy VS, Gouroju S, Suchitra MM, Suresh V, Sachan A, Srinivasa Rao PV, Bitla AR. Antioxidant defense in overt and subclinical hypothyroidism. Horm Metab Res. 2013 Sep;45(10):754-8

30. Tenorio-Velázquez VM, Barrera D, Franco M, et al. Hypothyroidism attenuates protein tyrosine nitration, oxidative stress and renal damage induced by ischemia and reperfusion: effect unrelated to antioxidant enzymes activities. BMC Nephrology. 2005;6:12.

31. Leena Rastogi,Madan M. Godbole,Madhur Ray, Priyanka Rathore,Sunil Pradhan, Sushil kumar Gupta,Chandra M. Pandey. Reduction in oxidative stress and cell death explains hypothyroidism induced neuroprotection subsequent to ischemia/reperfusion insult. Experimental Neurology.2006 Aug: 290-300. 